\title{
SI NO LO CULTIVAS, SÁCALO DE LA MINA ${ }^{1}$
}

\author{
Alegría Alonso González
}

Universidad de Salamanca

\begin{abstract}
RESUMEN
La transferencia de tecnología minera entre Hispanoamérica y España no ha quedado reflejado en nuestras obras lexicográficas. Un análisis de estas últimas revela que el corpus actual de términos marcados como Min es escaso en su numero y arbitrario en su selección, si lo comparamos con la realidad de uso en los textos mineros que dan cuenta de la lengua utilizada en los enclaves mineros hispanoamericanos. La revisión de estos tecnicismos en las distintas ediciones del Diccionario Académico y en diversas obras especializadas nos permite un primer acercamiento a la historia de la terminología minera.
\end{abstract}

PALABRAS CLAVE: tecnología minera, Hispanoamérica, España.

\section{SUMMARY}

The transference of minig technology between Hispanoamerica and Spain has not been reflected in our lexicograficas works. A analisis of these you complete reveals that corpus present of marked terms as Min is little in his I number and arbitrary in its selection, if we compared it with the reality of use in the mining texts that give account of the language used in the HispanoAmerican mining establishments. The revision of these tecnicismos in different editions from the Academico Dictionary and in diverse specialized works allows to a first approach to the history of terminologia miner us.

KEY WORDS: mining tecnology, Hispanoamerica, Spain.

No sólo las distintas evoluciones tecnológicas de la humanidad han venido precedidas del descubrimiento de un nuevo metal $^{2}$, también los grandes conflictos y guerras se han originado en la búsqueda e intento de controlar las materias primas. Nuestra sociedad ha dependido en gran medida de recursos

1 «If it isn't grown it has to be mined» fue el eslogan de una campaña de la Nevada Minig Association que, en traducción libre, hemos escogido como título de este trabajo.

2 Los principales hitos minero-metalúrgicos coinciden con los de la historia de la humanidad: Edad de Piedra, del Cobre, del Bronce, del Hierro, del Carbón, Revolución Industrial, Edad del Petroleo, etc. 
minerales y a las labores mineras ha dedicado buena parte de su actividad: desde las industrias líticas, pasando por las labores de extracción, refinamiento y aleación de los metales hasta llegar a la invención de la metalurgia, con sus múltiples aplicaciones técnicas actuales.

Dentro de la cuenca mediterránea España ha sido un territorio importante en recursos minerales desde la más remota antigüedad ${ }^{3}$ : explotaciones de cobre en la zona de Huelva que datan de la transición de la Edad de Piedra a la del Bronce; explotaciones argentíferas en la zona levantina, asi como en Cartagena y Linares, de época fenicia y tartesa; abundantes explotaciones de época romana que coinciden en buena parte con las actuales de Almadén, Río Tinto, Cartagena o Sil. La minería romana en nuestro país alcanzó un alto nivel, perfeccionado más tarde por los árabes. Aportaciones suyas de interés son, por ejemplo, la utilización del hierro para la fabricación de armas, el uso del mercurio para separar el oro (obtenido por destilación del cinabrio), el hallazgo en el siglo III d. C. de aleaciones como el peltre y el latón. Por lo que respecta a la Edad Media los cambios más importantes se produjeron en la utilización de maquinaria para el vaciado del agua de las minas y la extracción del material.

Con el descubrimiento de América, los españoles iniciaron el desarrollo de la minería americana, en estrecha relación con la de la península: el mercurio de Almadén se hizo imprescindible para la amalgamación del oro y plata americanos. La explotación minera del Nuevo Mundo fue, sin duda, la causa - económica - de la presencia española en aquel continente durante más de tres siglos ${ }^{4}$ : la producción minerometalúrgica colonial y el empleo de mano

3 El capítulo 7 de la Historia natural y moral de las Indias de José Acosta, «De la riqueza que se ha sacado, y cada día se va sacando, de el cerro de Potosí» puede ilustrar esta afirmación:

«Dudado he muchas vezes si se halla en las historias y relaciones de los antiguos tan gran riqueza de minas, como la que en nuestros tiempos hemos visto en el Pirú. Si algunas minas uvo en el mundo ricas y afamadas por tales, fueron las que en España tuvieron los cartaginenses y después los romanos; las quales, como ya he dicho, no sólo las letras profanas, sino las sagradas, también encarecen a maravilla».

4 Fue la búsqueda y explotación de los yacimientos de metales preciosos la actividad que impulsó la creación de nuevas ciudades y pueblos. Sirvan como ejemplo, en Chile La Serene, Concepción, Valdivia, Imperial o Villarrica. Resulta sumamente elocuente la opinión que Antonio de Ulloa nos ofrece en el Entretenimiento XIII de sus Noticias americanas acerca de lo que supuso para el mundo la explotación de los metales americanos: "Antes del descubrimiento de las Indias, y en lo que alcanza la memoria del Mundo, había Oro y Plata, que en todos tiempos han servido al destino que va expresado; pero después de aquel famoso suceso, han venido a ser el poderoso incentivo de mantener á todas las Naciones en movimiento, y de inducirles a un continuado empeño y emulación para adquirirlos. La solicitud de estos metales 
de obra indígena se orientaron a hacer rentables los recursos minerales y establecer un control real sobre el beneficio de los yacimientos, que llevó aparejadas importantes innovaciones tanto en las técnicas extractivas como en el tratamiento de la plata y el oro con mercurio.

Antes de la llegada de los españoles los pueblos aborígenes tenían actividades mineras, aunque, en un nivel de desarrollo bastante inferior al europeo. Las palabras de Antonio de Ulloa, en el Entretenimiento XIV de sus Noticias Americanas pueden dibujar la situación:

«La gran riqueza de las Minas antiguas está confirmada en la circunstancia de sacar Plata de ellas los Indios, porque estos no conocían otro beneficio que poner al fuego, en tiestos, el Metal donde la Plata estaba visible y abundante, y derritiéndose la recogían: en cuyo modo sencillo, sólo la que estaba limpia de otros metales podía fundirse. De esto ha nacido conservar el nombre de Cayana los hornos en donde se hace la fundición de la Piña; porque en la Lengua de los Yacas significa tiesto».

Y en los primeros años de la conquista el panorama no cambió demasiado: mientras que la minería europea del XVI utilizaba vagonetas de madera para transportar el mineral, disponía de sistemas de ventilación en las minas y aplicaba técnicas de entibado para evitar los derrumbes en los pozos, las explotaciones auríferas y argentíferas de Hispanoamérica continuaban utilizando a los terateros o a los apiris que en sus sacos o cotamas sacaban a las canchas el mineral que los barreteros habían desprendido. Las innovaciones técnicas difundidas en De Pirotecnia libri X (Biringuccio, 1540)o en De Re Metálica libri XII Agrícola, 1556) tardaron en llegar a las explotaciones del Caribe, México y Perú5. Muy pronto, sin embargo, se hizo necesario, trasvasar al nuevo continente la experiencia y conocimientos de los mineros españoles para la explotación y beneficio de los minerales. Así, tras unos primeros años en los que los peninsulares que se hicieron cargo de las explotaciones mineras eran soldados o navegantes, poco después se inició un verdadero

ha sido causa de civilizarse las gentes entre sí con el trato; de poblarse los Mares de flotas numerosas, que navegan sobre las aguas, como si fueran Republicas enteras; ha adelantado las Artes, sutilizado la industria, ilustrado las gentes, y les ha proporcionado el conocimiento de la tierra, que antes estaba muy incompleto, ignorándose muchas de sus producciones propias, y sus particularidades»».

5 En México, donde no existía una sólida tradición metalúrgica, se impusieron antes las técnicas europeas. En Perú, en cambio, los conocimientos técnicos autóctonos fueron suficientes mientras en Potosí o Porco abundaron los metales ricos y sólo con la escasez empezaron a resultar antieconómicas las guairas, hornos indígenas. La reactivación de la producción en esta zona, como antes en México, vino de la mano de la transferencia de técnicas europeas. 
proceso de transferencia tecnológica: si el primer sistema utilizado por los españoles en las minas de Nueva España fue la fundición ${ }^{6}$, ya en 1555 Bartolomé de Medina ${ }^{7}$ puso en práctica el que habría de revolucionar la minería de la época, la amalgamación o «beneficio de patio» utilizando el mercurio, sistema que arraigó en América - porque requería pocas inversiones, lo que compensaba su lentitud-, donde fue perfeccionado, primero por Gaspar Loman y más tarde por Alonso Barba con la amalgama en caliente en calderos de cobre, $\mathrm{y}$ donde permaneció vigente hasta mediados del siglo XIX.

En el siglo XVII se recurrió a la pólvora para procurar filones más ricos, si bien la innovación más importante de este siglo fue el horno de aludeles, que ahorraba combustible y reducía el riesgo de intoxicación. Este horno fue experimentado por Lope de Saaavedra Barba en Huencavelica y llevado inmediatamente a Almadén por Juan Alonso de Bustamante. Y ya en el XVIII la innovación más sobresaliente fue el malacate, en la minería mexicana y apenas utilizado en Perú, que servía para elevar agua o materiales desde grandes profundidades. No menos importantes fueron otros avances como los tiros verticales que unían pisos de galerías horizontales o las grandes haciendas de beneficio con martinetes, tahonas o arrastres.

Mientras que en materias como la Medicina o la Botánica la contribución americana al enriquecimiento de la lengua peninsular ha sido objeto de numerosos trabajos de investigación ${ }^{8}$, por lo que respecta a materias de carácter aplicado, como la que nos ocupa, ha sido menor el interés por parte de los estudiosos.

La minería, como actividad humana, no precisó de conceptualización previa, sino de transmisión de unos saberes quasi populares que se expresaban en lengua vulgar, como también lo hacían otras disciplinas eminentemente prácticas: navegación, arquitectura, ingeniería, albeitería, caza, etc. Los primeros españoles que entraron en contacto con la minería hispanoamericana se en-

6 El viejo método europeo de molienda y fundición que sustituyó a los autóctonos de Perú y Méjico.

7 Sevillano que se convirtió en minero al establecerse en Pachuca en 1553, tras fracasar como comerciante. Después de varios experimentos, en 1556 puso en práctica el método conocido como de «beneficio de patio»: el mineral molido se extendía en grandes patios donde se mezclaba con sal, magistral y mercurio; se lavaba después en grandes tinas, en las que los indios descalzos apisonaban el mineral con los pies para separar la amalgama de los elementos no metálicos; finalmente se aislaba la plata del mercurio por medio del calor.

8 GutiÉrRez Rodilla, B. (1998), La ciencia empieza en la palabra, Barcelona, Península, pp. 40-84, y la bibliografía allí utilizada serán nuestra referencia para la historia de la terminología. 
contraron con una realidad que conocían parcialmente: no tuvieron que nombrar nociones nuevas - como ocurrió con frutos o animales-, sino que unas veces asimilaron términos indígenas, otras buscaron la equivalencia en su propia lengua y otras impusieron voces castellanas para alcanzar el grado de comprensión que les permitiera realizar el laboreo en las mejores condiciones posibles.

Consideramos que la llegada de Cristóbal Colón a América en 1492 supuso un descubrimiento en ambos sentidos. El concepto de «encuentro entre culturas» no lo empleamos aquí para alejarnos de las connotaciones negativas del término descubrimiento, sino para explicar la transferencia tecnológica y lingüística que, en el caso de la minería, se produjo a partir de la histórica fecha entre España e Hispanoamérica: el intercambio de conocimientos y de las palabras que sirvieron para hacerlo efectivo.

De acuerdo con lo expresado por Bertha Gutiérrez (Gutiérrez 1998:40) «la terminología científica guarda una relación muy estrecha — que se puede demostrar históricamente - con el lugar geográfico donde se han ido realizando los principales descubrimientos científicos o técnicos, así como con la lengua en que estos se expresan», la terminología minera debe ofrecernos un buen número de términos procedentes de las explotaciones mineras hispanoamericanas, al servicio de la Corona española desde los primeros años del Descubrimiento, que pueden ser tanto términos patrimoniales del castellano (sean de procedencia latina, griega o árabe) que desde la lengua peninsular se incorporaron al español americano, como americanismos ${ }^{9}$ que penetraron en el español. En las líneas que siguen intentaremos evaluar la acomodación que el lenguaje técnico de la minería alcanzó en la lexicografía académica desde Autoridades a nuestros días en comparación con la realidad de uso de esos términos en los textos que conservamos, que son los que nos han permitido familiarizarnos con la lengua utilizada en los enclaves mineros hispanoamericanos.

\section{LA MINERÍA EN EL DRAE: UNA MINA DE PROBLEMAS}

Nuestro acercamiento al tecnolecto minero recogido en los diccionarios tiene en cuenta que el uso de marcas diatécnicas no siempre es homogéneo y

9 Consideramos americanismos las voces que diferencian al español del América del de la península y que pueden ser tantos términos procedentes de los dialectos y lenguas aborígenes como términos hispanos desusados en la península y que se han mantenido o han resurgido en alguna región de Hispanoamérica. 
con frecuencia es incongruente: algunas voces mineras aparecen marcadas únicamente con indicaciones sobre su etimología - procedencia de una determinada lengua indígena-, o sobre su uso en una zona concreta y no son pocas las voces que no presentan marca alguna. Debemos tener presente que las marcas temáticas no aparecen en nuestra lexicografía hasta 1780 y que la Academia las ha reestructurado en diversas ediciones, siendo la edición de 1884 la que afecta a nuestras consideraciones, por ser la que distingue entre Minería y Mineralogía; es también la que aumenta considerablemente el número de americanismos y será a partir de esa fecha cuando encuentren su sitio en el diccionario muchos de los términos que vamos a comentar.

La trascendencia social y económica que para España supuso el desarrollo de la minería en Hispanoamérica contrasta con la escasez de términos marcados como tecnicismos mineros que nos ofrece la Academia localizados o procedentes de aquel continente.

De las 264 entradas que DRAE 1992 marca con $\mathrm{Min}^{10}$., sólo yapa (del quechua) y callapo (del aimara callap) tienen procedencia indígena. Términos marcados con Min. que incorporen también alguna localización de uso en Hispanoamérica aparecen únicamente los siguientes:

TABLA 1

\begin{tabular}{|l|l|}
\hline AMÉR. & $\begin{array}{l}\text { NEGRILLO, NATA, BARRA, CAMPISTA, DESPILARA- } \\
\text { MIENTO, DESPILARAR }\end{array}$ \\
\hline AMÉR. MERID. & BROCEARSE, BROCESO, LLAPAR, YAPA \\
\hline CHILE & BOGAR, CALLAPO, DESPINTE, DOBLA \\
\hline MÉJ. & ARRASTRE, CABALLETE, CUESCO, CHACUACO \\
\hline NO. $A R G$. Y CHILE & REVENTÓN \\
\hline PERÚ & CONACHO \\
\hline
\end{tabular}

Escaso su número y arbitraria su selección: no todas las fases del proceso minero están representadas de una manera equilibrada ni todas las zonas ven recogidas sus voces específicas.

10 Hay que tener en cuenta que algunas de ellas son simples remisiones como adema / ademe, escapulario / escalera de escapulario, franco / terreno franco, labor / excavación, lave / lava 2, machacado / metal machacado, superficie / cánon de superficie. 
Para formarnos una idea de cómo se ha constituido el corpus actual de términos marcados como Min. en el DRAE hemos revisado esos doscientos sesenta y cuatro términos en las distintas ediciones en busca del momento de su incorporación y su posible evolución. Empezaremos diciendo que ya estaban presentes en el Diccionario de Autoridades ${ }^{11}$ con el mismo sentido o con muy pocas variaciones azoguero ${ }^{12}$, barra, bolsa, entibador, entibar, entibo y piña.

No aparecen, en cambio, en ese primer diccionario académico las formas adema, ademador, ademar, ademe, agogía, aguada, ahonde, andalucita, apure, arbolillo, aterrear, atibar, atierre, atinconar, azanca, bancada, barretero, bismutina, bismutita, bolsada, bonanza, brasca, brocearse, broceo, cajonero, calicata, calón, callapo, camada, campista, cateador, catino, cementar, cendradilla, cochizo, cochurero, conacho, corpa, chiscarra, denuncio, derrabe, desatibar, desatoar, deslamar, despilarameinto, despilarar, despinte, desviación, desviamiento, desvio, echado, encamación, encapado, encapillar, encarre, encofrado, encostillado, endoble, enmaderación, entrepiso, escopetar, estemple, ferrificarse, filón, fisura, jabeca, jaula, laboreo, lava, lave, licuar, llapar, metal machacado, mechazo, mineralizar, miñón, muletilla, nata, plecbenda, pegador, petanque, pileta, piso, plata de piña, pueble, punterola, recuñar, relave, remolido, revenimiento, rodado, salbanda, soplado, terreno franco, trecheador, trechear, trecheo, varada, yapa, zaca, zafra y zafrero.

Y el grupo más nutrido lo constituye el de las voces que ya aparecían en Autoridades, aunque con acepciones no relacionadas con la minería. En muchos casos la acepción que más tarde se incorporará con marca temática está incluida en una definición general o es lógicamente deducible, como ocurre en apartar, cabecera, cochura, ganga, encamarse garbillar y garbillo, tanda, lavar y lavadero. En otros casos se han creado usos metafóricos a partir de la entrada que aparece en Aut., como en dique, matriz, bolsa, bigote. En otros un tecnicismo de otro área, generalmente de Náutica, Arquitectura o Militar, ha desarrollado un significado técnico minero, como, atrio, capellina, contramina, hastial, lampazo, mena, metralla, compás.

En la edición de 1770 se incorporan unas pocas voces, entre las que destacamos, azoguería, que lo hace con la indicación inicial de «En Nueva Espa-

11 Para los problemas de selección del vocabulario técnico por parte de la Academia, vid. Gutiérrez Rodilla B. (1993).

12 Sin marca entonces, como «el que trata y contrata en azogues. En la villa Imperial del Potosí en Indias hai gremio de azogueros». En 1770 aparece con la restricción «En Nueva España», que mantendrá hasta la edición de 1852. Desde 1869 la marca será Méj, y a partir de 1884 aparecerá como Min. Idéntica andadura tendrá su derivado azoguería. 
ña», que conservará hasta 1852 y que en 1869 recibirá la marca Méj y a partir de 1884 Min.Y barretero que presenta entonces la restricción «en las minas».

En 1783 fueron escasas las incorporaciones. Destacamos adema porque el resto de términos de su familia - ademe, ademador y ademar- lo habían hecho en la edición anterior. A partir de este momento ademe será sólo una remisión a adema, voz que en la edición de 1925 incorporará una segunda acepción - «forro o cubierta de madera para asegurar tiros, pilares, etc».-

La edición de 1803 tiene entre otras novedades guía, marcado como Min, y con la definición de «Terreno o señal que está cerca de alguna veta o indica su proximidad o abundancia». Desde 1899 será «Vetilla a que algunas veces se reducen los filones y que sirve para buscar la prolongación». Lama, en cambio se incorpora sin marca, con la restricción «entre mineros», que conservará hasta la edición de 1869; a partir de 1884 aparece con la marca temática y definido como «Harina o tierra sutil de los metales», definición que en la siguiente edición, la de 1899, se convierte en la que llega hasta la actualidad: «Lodo de mineral muy molido que se deposita en el fondo de los canales por donde corren las aguas que salen de los aparatos de trituración de las menas». Por su parte lava se definirá «En las minas se llama así el baño o loción que se da a los metales para limpiarlos de las impurezas» hasta la edición de 1869 y la marca Min se le añade en 1884, como a tantos otros términos mineros. En 1925 se redacta la definición que llegará a nuestros días: «Operación de lavar los metales para limpiarlos de impurezas». También encuentra su lugar en la lexicografía académica en este 1803 la voz negrillo, de la que se nos dice que «Se aplica a ciertas piedras metálicas de las quales se saca plata de muy buena calidad»; en 1817 se transforma en: «Nombre que dan los mineros a la variedad de la plata nativa que es de color negro», definición que se repetirá en 1884, cuando la Academia decide marcarla como término específico de la minería; una nueva redefinición y remarcación sufrirá en 1914: «Min. Amér. Mena de plata cuprífera cuyo color es muy obscuro».

De la edición de 1817 destacamos mena, como «La veta del mineral y el mismo mineral», que a partir de 1869 será «Min. Los minerales o metales mezclados todavía con la ganga o con la piedra y tierra de la mina»; en 1884 se indicaba que procedía del celta men 'piedra', mientras que en 1992 se le atribuye la misma procedencia que a mina 2 , esto es, el francés mine.

La de 1822 incorpora sólo unos pocos términos, entre los cuales nos hemos fijado en mineralizar porque entró con la marca Quím. y definido como «Reducir un metal a forma de mineral» y en 1884 se cambia por Min. y se 
ofrecerá la definición que ha llegado hasta hoy: «Comunicar a una sustancia las condiciones de mineral o mena».

En 1869 barra entra con una doble caracterización a través de las marcas: término minero usado en América. Se le añade la marca a dos términos incorporados en 1852 sin ella, como son filón y ganga. Se acepta además la voz mechazo, como Min., aunque con una definición poco técnica: «Se dice de un barreno cuando se consume la mecha sin inflamarse la pólvora», que a partir de 1884 será: "Combustión de una mecha sin inflamar el barreno. U. por lo común en la fr. dar mechazo». La voz miñón que desde 1817 aparecía para designar un soldado de tropa ligera en esta edición de 1869 incorpora dos nuevas acepciones ${ }^{13}$ : «En algunas provincias, la escoria del hierro. / Min. Mena de hierro de aspecto terroso»; esta última en 1989 cambia la marca por Min. pr. Vizc. y en 1914 por Min. Vizc.

Del grupo de doscientos sesenta y cuatro términos que hemos tomado como punto de partida son novedades en 1884 bigote, que en esta edición recoge dos sentidos técnicos de la minería: llamas que salen de la bigotera del horno e infiltraciones del metal en las grietas del interior del horno; en 1899 se aceptará una nueva acepción, también de la minería: abertura semicircular en los hornos de cuba para que salga la escoria fundida. Caña entra referido sólo a las minas de Almadén, restricción que desaparecerá en la edición de 1899. El término contramina llegó al Diccionario en 1780 como segunda acepción de la entrada, pero sin marca temática hasta la edición de 1884 . Criadero presentaba en su debut académico una definición sencilla y comprensible — «Sitio abundante en algún mineral»— que se convirtió en 1914 en la más rebuscada y oscura "Agregado de sustancias inorgánicas de útil explotación que naturalmente se halla entre la masa de un terreno». Y encamación consigue ahora su derecho a marca Min, aunque estaba presente en el DRAE desde 1791 con la delimitación en la definición «en las minas». Denuncio en esta edición y en la de 1899 aparece marcada como Min, pero con una simple remisión a denuncia, en 1914 y 1925 como «Min. Acción de denunciar una mina» y a partir de 1936 incorpora una segunda acepción: «Concesión minera solicitada y aún no obtenida». Sólo aparecerá definido en esta edición que le dio entrada estemple, que en las sucesivas se convierte en una remisión a ademe. Por su parte jábeca ${ }^{14}$ definido aquí como «Aparato destilatorio que se usaba antiguamente en Almadén para el beneficio de los minera-

13 Que a patir de 1884 se recogerán en una entrada independiente.

14 La propia Academia ha vacilado de unas ediciones a otras entre acentuar la palabra o no. La última hasta ahora es con acento. 
les de azogue, en la siguiente edición, la de 1899 ya se considera «horno de destilación» y se ofrece una descripción pormenorizada del mismo.

En la edición de 1899 también son numerosas las novedades en cuanto a voces de la Minería. Así, se incorpora amainar, mientras que su derivado amainador no lo hará hasta 1925. En la edición anterior había entrado chacuaco con una única acepción - Mej. Horno pequeño para fundir metales-, que ahora consta como «(Voz americana) Min. Horno de manga para fundir minerales de plata» y que en 1992 ofrece la misma e incorpora una segunda: Mej., chimenea, conducto. Dos voces entran juntas en esta edición, la una - desatibar-como remisión a la otra - desatorar - hasta 1927 en que obtiene el derecho de definición. Dos acepciones recoge de fajado si bien la segunda - madero en rollo para entibar pozos - no consiguió el distintivo Min. hasta 1914.

En la edición anterior ya aparecía haba, sin marca, como «Gabarro cristalino fuertemente adherido al sillar en que se encuentra», acepción que a partir de ésta se convertirá en un reenvío a la acepción correspondiente de gabarro, incorporando a la vez una nueva que recoge el sentido de 'trozo de mineral más o menos redondeado y envuelto por la ganga'. Desde su aparición como tecnicismo minero en esta edición de 1899 la Academia ha resuelto labor con una remisión a excavación y con la indicación $U$. m. en plural. Además de Min. nata presenta la marca Amér. desde su incorporación en esta edición.

En 1914 la Academia aumenta su corpus de tecnicismos mineros con voces como atibar, que lo hace en el Suplemento y cochura y cochurero, ambas con la restricción, dentro de la definición de «en los hornos de Almadén».

La edición de 1925 es también importante para la terminología minera del $D R A E$, que da entrada a términos como broceo, que lleva también la etiqueta Amér. Merid., caballete, que es la forma Mej. de decir caballo, según el Diccionario académico, campista y ateador, que llevan además la marca Amér, mientras conacho lleva además Perú - es el único término marcado como Min y Perú a la vez-, despilarar la etiqueta Amér. y despinte la de Chile, compás, en el que se añade la marca Min. a la acepción que en 1899 se había marcado sólo con Mar.

Andalucita y bismutita — que no consiguió el distintivo Min hasta 1992fueron acogidas por la Academia en 1927. Ambos términos nos muestran en el $D R A E$ falta de organización conceptual de las áreas temáticas Así carbonato es un término marcado como Quím., mientras bismutita, definida como «carbonato natural hidratado de bismuto» es considerado término de la Minería. Otro tanto ocurre con silicato (Quím.) y andalucita (Min.) «silicato de alúmina natural». 
En 1936, entre otras, entraron cuesco, una de cuyas acepciones mineras aparece también como Méj. y dique, que desde 1899 a 1925 mantuvo la marca Geol., aunque la definición era la misma que podemos leer en la última edición, y en el volumen que apareció en 1936 se cambió por Min.

Del año 1947 es la edición que acogió a una de los tecnicismos de la minería más crudos que podemos encontrar en DRAE: pecblenda, préstamo del alemán que designa a un determinado mineral de uranio.

En 1989 el derrumbamiento de una mina encuentra su expresión técnica en el término derrabe, mientras que en 1992 entra bismutina. También en este año deslamar, que estaba presente ya en el DRAE desde 1791 sin marca y como «quitar la lama», sufre un cambio en la definición - «Limpiar un material de sus fracciones más finas»- y consigue la marca técnica. Y desviamiento, que desde 1970 a 1989 era, sin marca, un «cruce de una vena mineral con otra» pasa a tener marca y se convierte e una remisión a desvio.

\section{LA MINERÍA EN LOS TEXTOS: UN FILÓN PARA EXPLOTAR}

Ya hemos apuntado que en el corpus de Minería del $D R A E$ no están todos los que son: términos pertenecientes al ámbito minero que carecen de marca temática, aunque disponen de marcas de uso o de origen etimológico americano, forman también parte del Diccionario. Por este motivo hemos recurrido a la lectura de algunas obras para entresacar algunas voces que parecen haber gozado de cierta difusión, aunque muchas de ellos no llegaron nunca a los diccionarios generales ${ }^{15}$ o tuvieron un paso efímero por ellos, como anco, o desaparecieron por considerarse desusadas o anticuadas en la metrópoli. Y, sin embargo, son esos términos los que nos muestran los resultados del fecundo contacto entre españoles e indígenas. Consideramos que la veta principal en la búsqueda que planteamos ha de ser el Diccionario y maneras de hablar que usan en las minas de García de Llanos (Molina Barrios:1983) ${ }^{16}$

15 Cabría preguntarse si algunas de las voces de origen quechua, aimara o nahua, con significados que las sitúan en el campo de la minería, estarían presentes en nuestros diccionarios si hubieran tenida una procedencia etimológica diversa, flamenca, francesa o latina, por ejemplo.

16 Ningún repertorio bibliográfico cita obra alguna anterior a la de Llanos. Y con posterioridad sólo encontramos que en 1761 aparece la obra de F. Javier de: Gamboa, De la significación de algunas voces obscuras usadas en los minerales de Nueva España., en 1791 se publicó el Mercurio, de 1890 es el borrador del inconcluso Diccionario minero hispanoamericano de Ernesto O. Rück y en 1945 se imprimió la obra de Stubbe 
porque es la primera compilación formal y especializada sobre la minería colonial de que disponemos y porque, como hemos apuntado (Alonso González:2002) ofrece un panorama bastante completo de todos los aspectos que se pueden considerar en la minería: desde los tipos de metales a los procesos de extracción y beneficio, pasando por la maquinaria y herramienta empleadas, los diferentes obreros especializados y la situación social y legal.

Para verificar la validez de los datos recogidos por García de Llanos hemos consultado algunos tratados relacionados con la minería, como los de Barba o Pérez de Vargas, y obras de escritores europeos que dan cuenta de la realidad americana, como Acosta, Antonio de Ulloa ${ }^{17}$ o Acarate du Biscay. Lo que ofreceremos ahora es sólo una calicata, dejando para otros trabajos más extensos la verdadera explotación y beneficio de los mismos.

De las 258 entradas que García de Llanos recoge, DRAE 1992 da cabida a las siguientes ${ }^{18}$ :

a chiflón y achiflonarse (s.v. chiflón), achupas (s.v. achura), aquijado (s.v. quijo), apiri, ataucado y ataucar (s.v. tauca), ayllo (s.v. ayllu), barbacoa, calichal (s.v. callapo), cancha, cimba, coca, cocaví, cochas (s.v. cocha), viracocha, coya, concho, cotamas (s.v. cutama), huasca, chasquear y chasquis (s.v. chasqui), chile (s.v. chile), chumbe, pallar, guasca, galpones (s.v. galpón), bohío, curaca, huasis (s.v. guaso), huaicu (s.v. huaico), huaira, huairar y huairadores (s.v. guaira), huasca (s.v. guasca), llancana y llancar (s.v. llanca), mingar indios y mingas (s.v. minga), mita y mitayos, paco, palca, pallar, pampa, pirca, pongos (s.v. pongo), quipi (s.v. quipu), quisca, taucado y taucar (s.v. tauca), pallaco, topo.

En su Diccionario encontramos algunos términos que nunca tuvieron un espacio en la Academia, como vilaciques, que García de Llanos, s.v. metal, párrafo 22, define así:

«Quiere decir ciques colorados, porque tienen unas manchas de este color y vila en la aymara quiere decir 'sangre'. En lo demás son del color mismo de los ciques, porque lo son, que solamente se diferencian en esta señal, que lo es de riqueza. Y, así, tienen mucha más ley que todos los demás metales de caja, y tanta como los razonablemente buenos de vetas y que han competido con metales ricos de ellas. Están ya muy apurados y no se halla sino una piedra acaso. Fueron los mejores de

17 Fue el primer director del Gabinete de Historia Natural de Madrid, en 1752, y, tras renunciar a este cargo se trasladó a Hispanoamérica como gobernador y superintendente de Huancavelica.

18 Ponemos entre paréntesis la forma que aparece en el D.R.A.E., cuando ésta no coincide con la de García de Llanos. 
la Muñiza, cierta parte de la Veta Rica al sol del Cerro, y no se han hallado hasta ahora vilaciques sino en Potosí».

Y que Alonso Barba explica en este fragmento:

«Ciques llaman a las otras piedras que nacen con los metales, o a sus lados, que también se dicen caxas; son toscas y no muy duras ni macizas; no participan de metal de ordinario, aunque en algunos minerales y vetas ricas también se les pega algo de su vecindad. Famosos han sido y son los vilaciques de este riquíssimo cerro de Potosí, por la mucha plata que de ellos se ha sacado, y no es ésta la menor prueba o alabanza de su propriedad sin igual. Vila significa sangre o cosa colorada, en la lengua natural de esta provincia $y$, por unas pintas o señales pequeñas que tienen de este color, llaman a las piedras vilaciques.»

\section{Tampoco es académico puruña, que para Llanos s.v.:}

Es en la general vasija o almofia de barro cocido. Es cosa ordinaria en los ingenios para ensayar

Mientras que Barba nos ofrece varios ejemplos de su uso:

«Descúbrese como una ceja en la puruña, quando el metal se ensaya, y de ella toman los experimentados indicación de la calidad del metal y estado de los caxones».

«...muéstrase la lis de azogue muy sutil, blanca, sin viveza, y al baxar el relabe con el agua de la puruña, no corre, antes se va quedando como pegada al suelo y, si con el dedo se refriega, se junta en granos de azogue vivo».

Y Stubbe s.v. poruña indica su uso en Argentina, Chile y Bolivia como «un pequeño receptáculo alargado, hecho de un cuerno de vaca, cortado longitudinalmente, en el cual hacen los mineros la primera, rápida prueba de las arenas de aluvión para ver si contienen oro».

Tuvo su momento de gloria anco, introducido en la edición académica de 1817 con la etiqueta Min. y definido «Lo mismo que plomería», pero sólo pervivió hasta 1869. García de Llanos s.v. metal con toda profusión de detalles nos explica que:

«Quiere decir en la general nervio, y en los metales significa plomo por metáfora y semejanza, porque partiéndolo hace correa si tiene mucho plomo, a cuya causa le dieron los indios este nombre, aunque tenga el metal tanto menos que no pueda servir de nervio. El buen anco o plomo es grueso y casi negro, del mismo color que él se tiene no estando en el metal, sino solo. Y los metales de plata que por donde- 
quiera que se partan muestran y descubren mucho plomo de éste son ricos, y algunos no se diferencian en ley del metal tacana, antes en rigor es lo mismo, que sólo se diferencia en tener aquella señal de riqueza más que estos otros, de manera que todo metal tacana tiene plomo o anco, mas no al revés, que todo metal que tenga anco será tacana. Finalmente, todos los metales pacos en general se tienen por de más o menos ley según el plomo tienen, y no hay otra manera de conocerlos en piedra sino ésta. Y cuando el anco o plomo es grueso y todo el metal plancheado de él por dondequiera que se parta, es lo más que puede tener y se dice por encarecimiento que lo pueden cortar con un cuchillo. Y pasando la uña por encima, señala en él como en un pedazo de plomo ordinario. Otras veces se halla muy menudo y como puntillas muy sutiles que apenas se descubre y es menester destreza para echarlo de ver, que también siendo mucho es señal de riqueza. Y otros se ven en algunos olas o huequecillos que tiene el metal, como cabezas pequeñas de alfileres de su mismo color de plomo, a que llaman dados de plomo. Sin el cual hay otro plomo que dicen los indios comereanco, que quiere decir plomo verde, porque lo es, y se descubre y parece más que el primero, mas no tiene que ver con él en ley porque, aunque es bueno a falta de otro mejor, es mas pobre y se halla en metales que lo son. Además de los cuales, hay otro plomo que llaman volador, del mismo color y parecer que el bueno que primero se dijo, mas no se halla sino en las junturas y coyunturas de algunos ciques sin género de ley y no dentro del migajón, y en dándole con la mano se cae. Tiénese por común manera de hablar, en tratándose de metales, que no hay más ciencia en ellos que ancoyo, manancoyo, que es decir, no hay más que saber para conocer de ellos el bueno y el que no lo es, que si tiene plomo o no lo tiene, y es así.»

\section{Barba lo utiliza en varias ocasiones:}

«Ordinaria cosa es ésta en las vetas que crían anco o plomería, y experiencia común entre mineros, que también, como con la vista hacen prueba con el olfato, del metal que aún no conocen.»

«Hay metales muy ricos sobre ellas, llenos de anco, o plomería, y a los que más ordinariamente acompaña, son los cobrizos.»

«Y esto particularmente sucede quando se cuecen metales de mucho plomo gruesso, que llaman anco, que, como queda dicho, es plata bruta».

\section{$\mathrm{Y}$ en el Vocabulario minero antiguo de Stubbe encontramos el mismo concepto con la denominación anquería.}

Tampoco tuvo gran trascendencia el paso de llampo por la Academia: fue novedad en la edición de 1927 como «Chile. Polvo o tierra metalífera que suele hallarse en las oquedades de las minas» y así se mantuvo en la de 1950, donde reapareció. En 1984 y 1989, su tercera y cuarta aparición fue desplazado 
a segunda acepción, siendo la primera para el regionalismo andaluz en el sentido de 'relámpago'. Stubbe lo recoge en dos entradas dando cuenta tanto de su procedencia del quechua llampu, 'blando', como de su uso regional en Bolivia como «pequeños cristales de cassiterita dentro de una arcilla blanca...».

El Diccionario de Llanos lo recoge como

«llampos: Dícese de llampu, que en la general significa cosa blanda y suave al tacto, y así se les da este nombre a las tierras muy molidas que se causan de los metales partiéndolos y de la lama y tierras que en las vetas se halla a vuelta de ellos. Y, así, hay llampos de estos en las labores tan ricos como el mismo metal y más, sin los cuales hay otros que se juntan, pallan y recogen en la haz de la tierra donde ha habido canchas y buhíos que han tenido buenos metales, que son de la utilidad que los pallacos como se dirá.»

Azarosa ha sido la presencia de quijo en los diccionarios académicos. Entró en 1817 como «Especie de piedra sumamente sólida y dura, en que regularmente se cría el metal en las minas. Es voz usada en las Indias y principalmente en el reino de Perú» y mantuvo esta redacción hasta 1899, si bien en 1884 se sustituyó «en las Indias» por «en América». En 1899, con la misma indicación de uso de la edición anterior se definió como «Cuarzo que en los filones sirve regularmente de matriz al mineral de oro o plata». Esta definición se mantendrá hasta nuestros días, aunque la información con que fue acompañada también sufrió modificaciones: En 1984 se indicaba que procedía del latín "capsus, caja», mientras que en 1992 ya se indica que procede del aimara kisu kala; en 1985 y 1989 se marcaba como voz de Chile y Perú y en 1992 ya se considera voz propia de América en general. Stubbe ofrecía una definición general como «Ganga y generalmente la ganga cuarzosa» y otra localizada en Cerro Negro, Famatina y Argentina como «cuarzo con inclusiones de plata nativa y diferentes minerales de palta, o de una galena de grano fino y muy argentifera». Para García de Llanos los quijos

«... son metales pobres y en el nombre se echa de ver que lo mismo es quijo que guijo o guijarro. Tratando de piedras, y así lo parecen y bien ordinarias, su color es pardisco que tira algo a azul...De algunas vetas se dice comúnmente que van en quijos, mas a la hora que forme veta se puede tener por metal aquijado y no quijo».

Y Barba escribe:

«Llaman quijos a las piedras de casta de guijarros, que participan de oro, o plata, o otro metal qualquiera, y son de mayor duración y fundamento las vetas que sobre aquesto arman.» 
Pallar fue aceptada por la Academia en su edición de 1803 — junto a pallón - y hasta 1884 aparecía sin marca alguna como «Entresacar o escoger la parte metálica, o más rica de los minerales». En 1899 se indicaba que procedía de palacra 'grano de oro', aunque se daba entrada a pallador como procedente del quichua paella, campesino, con el significado de «coplero y cantor popular y errante en la América del Sur». Recogen pallaquear como variante peruana de pallar, las ediciones de 1884, 1899 y 1992. Esta última nos ofrece palla, usado en Argentina y Chile como «Selección de los minerales según la ley de los mismos» y usado en Chile como «Canto del pallador»; pallaco, del quechua pallákuy, «recoger para sí Mineral bueno que se recoge entre los escombros de una mina abandonada»; pallar, indicando su origen en el quechua pállay; pero pallador, con el mismo origen, sólo lo ofrece como «cantor popular errante», usado en América Meridional.

Pallar está incluido en la obra de García de Llanos con una definición enciclopédica en la que da cuenta del uso de otros derivados:

«pallar: Dícese de pallani, que en la general quiere decir coger del suelo, como cuando se coge grano a grano. Hay en el Cerro tres maneras de pallar. Una es pallar en la haz de la tierra, que es rebuscar desmontes y todo lo que en ella hay que se pueda aprovechar, así desecho de las minas y canchas, como quitamama. Y lo que así se junta se dice pallaco, lo cual se vende por cargas para revolver con otros metales, y los indios que se ocupan en esto se dicen palladores, que por la mayor parte son uruquillas, porque los de aquel pueblo tratan de éstos. De esta manera de pallar también se dice repallar al volver a rebuscar de nuevo lo que ya se ha pallado; y hay desmontes que se les han dado así muchísimas vueltas. También algunas personas tratan de juntar de estos pallacos con indios que alquilan y los revenden y benefician, y otros, asimismo, que traen labores a metal en las minas echan también indios a rebuscar en ellas, todo lo cual se dice pallar. La segunda manera de pallar es limpiar el metal en las canchas donde se pone luego que se saca de las minas, como se dijo en la palabra cancha, $\mathrm{n}^{\mathrm{o}} 36$, que es apartar lo malo y desecharlo sin recibirlo en cuenta de lo que a cada indio se le manda sacar, y los que hacen esto se dicen palliris, en que de ordinario se ocupan muchachos y algunos indios viejos. En esta manera de pallar, quiere decir repallar volverlo a limpiar. La tercera y última se dice pallar el tomar cuenta a los indios de lo que cada uno ha trabajado y sacado, como se dijo en la palabra días de cancha, $\mathrm{n}^{\circ}$ 91, y dícese así porque en acabando de tomarles cuenta, recoge cada uno al buhío el metal que sacó, cogiéndolo del suelo [pág. 98] (que es pallar), aplicándolo los españoles a lo que precede, $\mathrm{y}$, así, se dice pallar los indios al tomarles cuenta y asentarles lo que han trabajado, lo cual, asimismo, se dice quilcar, como se dirá en su lugar, y por qué razón en la palabra quilcar, $n^{\circ} 202$. Sin las maneras de pallar referidas, hay otra en la ribera donde están los ingenios, que es andar en ella al rebusco del azogue y pella que se lleva el agua del beneficio cuando sale de las tinas, en que se ocupan más mujeres 
que indios, y hacen para el efecto pozuelos en que se va juntando y de ellos sacan la arena que se recoge y, lavándola en bateas, apartan el azogue y pella que se junta; y éstos se dicen palladores de la ribera o de pella.»

Barba también lo utiliza:

El buen acierto para sacar la ley a los metales, comienza a zanjarse cuando se pallan o escogen

En las Noticias americanas de Antonio de Ulloa, quien declara que los mineros «usan de un lenguaje particular de Minas, que tiene la virtud de apartar de la imaginación todo otro asunto, y de recrearla» encontramos también pallaco y pallaquear. Y Stubbe incluye en su obra tanto pallacos, como pallador y pallaquear o pallar.

Llanos ofrece numerosos datos de interés no sólo en las entradas, también algunas definiciones internas tienen interés lexicográfico. Nos detendremos un poco más en una de ellas: carnerero, que, a nuestro entender, es un ejemplo de transferencia lingüística de ida y vuelta España-HispanoaméricaEspaña. Aunque pueda parecer a primera vista una palabra ajena al campo terminológico de la minería, la lectura de algunos textos nos convence de lo contrario. Encontramos abundantes referencias a los «carneros de la tierra»y su utilidad para la minería hispanoamericana. Juan del Pino Manrique en su Descripción de la villa de Potosí y de los partidos sujetos a su intendencia nos informa de que

«El trueque, cambio y venta de carneros de la tierra, que crían en crecidos rebaños, les ofrece también tal cual pasadía, por la estimación con que los conducen al mineral de Guantaaya, y Asiento de Tarapaca de la intendencia de Arequipa, por lo escaso de estos en todo comestible».

\section{Antonio de Ulloa en Noticias americanas afirma que}

«El animal mas útil para los Indios, y que se acomoda mas á su carácter es la Llacma, ó Carnero de la tierra: con él hacen toda suerte de carguíos, no solo en las minas, sino para transportar lo que se ofrece de unas partes á otras[...] Los Metales se conducen de las Minas á los Asientos en Llacmas, ó Carneros de la tierra, y en Alpacas».

Acarate du Biscay escribe en la Relación de un viaje al Río de la Plata y de allí por tierra al Perú con observaciones sobre los habitantes, sean indios 
o españoles, las ciudades, el comercio, la fertilidad y las riquezas de esta parte de América:

«Entre estos salvajes ordinariamente eligen los mejores obreros para separar la ganga entre las rocas, lo que hacen con barras de hierro que los españoles llaman palancas, y otros instrumentos de hierro; otros sirven para acarrear lo que excavan en canastitas, hasta la entrada de la mina; otros para ponerlo en sacos y cargarlos sobre una especie de grandes ovejas, que llaman «carneros de la tierra»: son más altos que los asnos y comúnmente llevan un peso de doscientas libras. Estos animales sirven para llevar el mineral a las casas de laboreo que están en la ciudad a lo largo del río, que viene del lago del cual he hablado antes».

A los hispanohablantes no puede sorprendernos que la persona que cuida esos «carneros de la tierra» sea el carnerero, no porque conozcamos en la península pastores dedicados exclusivamente a los rebaños de machos ovinos, sino porque es la formación esperable de acuerdo con nuestras reglas morfológicas y porque culturalmente es un término cercano y no perturbador. Ausente del Tesoro de Covarrubias, aparece por primera vez en una obra lexicográfica en el Diccionario de García de Llanos, de 1609:

«bajas: Dícense bajas la bajada de los metales del Cerro a los ingenios. Y, así, dar un minero el trajín de los suyos a un carnerero (que son los arrieros que los bajan), se dice que le da sus bajas; y tener el carnerero muchos fletes de éstos, dicen tener muchas bajas; y preguntar a cómo andan las bajas es como decir a cómo se baja o fleta el metal por quintales».

«chacanear: Dícese de chacnani, que quiere decir cargar y trajinar como lo hacen los arrieros. Y, así, aunque generalmente se entiende chacanear en cualquier género de trajín o acarreos en Potosí, se toma entre la gente del Cerro por lo más principal, que es el trajinar el metal de las minas a los ingenios, lo cual se hace en carneros que para el efecto tienen los tratantes de esto o carnereros. Y carga cada uno de seis a ocho arrobas y a veces más. Tienen los dueños cantidad de ellos en los pastos de la comarca, a diez, a quince y veinte leguas y más del asiento, para remudar; y los que vienen al trajín, cuando les cabe se dice mita como en los indios, porque les toca la vez de trabajar, y duran en el chacaneo de tres a cuatro semanas, con lo cual no quedan de provecho en un año, así por no ser para más, como porque casi no comen en este tiempo, respecto de no haber pastos junto al asiento ni en su comarca. Los indios que sirven de arrieros se dicen chacanas o chacaneadores y el trajín chacaneo.»

El primer diccionario académico lo recoge como «El que conduce los hatos de carneros y los lleva por su cuenta» y alega la autoridad del Padre 
José de Acosta en el libro IV de su Historia natural y moral de las Indias: «Tienen sus paradas sabidas los carnereros que llaman, que son los que llevan estas recuas». Después de ese debut la Academia ha mantenido el término en todas sus ediciones. El Histórico no aporta novedad alguna: la misma definición y como documentaciones Acosta y el propio Autoridades. Carnerero ha llegado a nuestros diccionarios actuales y aparece definido como «Pastor de carneros» no solo en $D R A E$ 1992, sino también en María Moliner, Casares, $D E A$ e incluso en enciclopedias como Larousse. El DEA allega un ejemplo entresacado de Usos y decires de la Castilla tradicional (Emilio Martín Calero:1984): «El rabadán y carnerero, ayudados por los zagales, también tenían su labor». El CORDE nos devuelve tres localizaciones de la palabra, dos de las cuales corresponden a la obra de García de Llanos, que ya hemos visto, y una tercera presente en Documentación medieval de la Corte del Justicia de Ganaderos de Zaragoza (1472-1492) que califica a un tal Peyrot como «carnerero, pastor suyo».

Con todos los datos que acabamos de repasar, creemos que carnerero hizo su entrada en el limbo académico referido a la acepción regional, esto es al «carnero de la tierra», nombrado así por los españoles que por primera vez vieron las llamas y que disponían de un referente peninsular para denominarlas - el macho de la oveja. La existencia del término con anterioridad al Descubrimiento sólo cuenta con el apoyo de ese único ejemplo en documentación medieval de Zaragoza ${ }^{19}$, en cambio, tras la conquista el vocablo se hace más frecuente y su presencia en Autoridades se debe, sin duda, a su uso por parte de Acosta.

Aunque el análisis que podemos hacer basándonos en los términos que acabamos de comentar no es exhaustivo, si nos permite apreciar que la realidad de la lengua de especialidad relacionada con la minería y la realidad que recoge el Diccionario de la Academia son bien diferentes. Aun aceptando que los diccionarios generales no son el espacio lexicográfico adecuado para los tecnicismos, puesto que en nuestra tradición lexicográfica no se ha respetado, aunque si reconocido, esta independencia, hemos tomado como referente la presencia/ausencia de los términos mineros en la Academia. Hemos podido comprobar que términos documentados en obras literarias y científicas nunca encontraron su espacio en la Academia; otros gozaron de un efímero paso por

19 Que, por otra parte, podría estar relacionado con carnerear en el sentido de sacrificar animales. 
sus páginas; otros fueron recogidos con acepciones que nos responden al sentido con que las usaron los autores que hemos revisado.

Pensamos, además, que algunos de los términos que entraron en el paraíso académico lo hicieron por su condición de americanismos, no de voces específicas de la minería. Así la Academia incorpora apiri - que para García de Llanos «en las minas son los indios que se ocupan en sacar el metal que otros barretean o juntan en la mina a la haz de la tierra»— en su edición de 1914 como voz aimara, que a partir de 1925 aparecerá ya como de origen quechua, pero que en ningún momento ha tenido marca diatécnica. También carece de marca temática cochas que en 1780 «En el beneficio de los metales es lo mismo que un estanque que se separa con una comporta de la tina o lavadero principal», acepción mantenida en 1992 y a la que se ha añadido /2 Ecuad. «Laguna, charco»; en 1925 ya señala la procedencia del quechua, mientras que la edición de 1899 todavía afirmaba que era del latín cochlea.

Otro tanto ocurre con guaira, introducido en DRAE 1989 —aunque, según el $D C E C H$; aparece documentado en Cieza de León en 1554 y en Lic. Cepeda en 1590, y, como hemos comprobado, en 1609 en García de Llanos-, como «Del quechua guaira, viento. Hornillo de barro en que los indios fundían los minerales de plata».

Y lo mismo podemos comprobar en callana, del que ya desde DRAE 1925 indica tanto su origen quechua como su uso en América, sin marcar que «escoria metalífera que puede beneficiarse» sea un término técnico. (En 1914 aparecía con la acepción de «vasija tosca que usan los indios americanos para tostar maíz o trigo» que se mantiene en 1992.)

Pirca es otro ejemplo de lo mismo, que ya en 1989 aparecía como «Del quichua pirca, pared. Chile. Pared de piedra en seco» y que en 1925, 1927, 1992 amplia su uso a Amér Mer. La primera documentación que ofrece el $D C E C H$ es de 1875 , en el Diccionario de chilenismos. No recogen, en cambio pirquiris, que encontramos en García de Llanos como «Los indios diestros de hacer estas pircas y reparos (que los hay con mucho extremo), se dicen pirquiris, y son los mismos que se nombraron ayciris o llamadores en la palabra ayzar, $\mathrm{n}^{0} 7$. Son muy estimados y con razón»

\section{CONCLUSIÓN}

De los datos vistos hasta aquí podemos colegir que el rigor terminológico no es precisamente una característica del trabajo de la Academia en el ámbito de la Minería, ni en los aspectos onomasiológicos, ni en los semiológicos, como 
revela lo ocurrido con bismutita y andalucita. Por otra parte, la selección de términos responde a criterios poco homogéneos: junto a voces específicas de un área minera muy reducida - cochura, cochurero y jábeca en Almadén, cuesco en Riotinto, encarre en Andalucía, altar y miñón en Vizcaya-, encontramos términos de uso más general como barretero, entibar, adema, o ganga.

Poco coherente resulta también el diferente tratamiento en cuanto a la marca diatécnica de Minería de palabras derivadas de una misma raíz, como podemos ver en el Cuadro 2:

CUAdro 2

\begin{tabular}{|c|c|}
\hline MARCADOS & NO MARCADOS \\
\hline AZOGUERÍA & AZOGUE \\
AZOGUERO & AZOGARSE \\
\hline AMAINADOR & AMAINE \\
AMAINAR & CATA \\
\hline CATEADOR & CENDRA \\
\hline CENDRADILLA & CENDRAZO \\
& ACENDRAR \\
& ACENDRADO \\
& ACENDRAMIENTO \\
\hline GARBILLAR & GARBILLADOR \\
GARBILLO & REPASO \\
\hline REPASAR & REPASADOR \\
\hline BARRA & BARRETEAR \\
\hline BARRETERO & MINERAL \\
\hline MINERALIZAR & \\
\hline
\end{tabular}

Igualmente resulta sorprendente la relación marcado/no marcado que, como muestra el Cuadro 3, apreciamos en términos que si no son sinónimos, si son equivalentes desde el punto de vista de la Minería: 


\section{CUADRO 3}

\begin{tabular}{|c|c|}
\hline MARCADOS & NO MARCADOS \\
\hline ÁBACO & $\begin{array}{c}\text { TINA } \\
\text { BATEA }\end{array}$ \\
\hline ALARIFE & PIRQUIRI \\
\hline AMAINADOR & APIRI \\
\hline APARTADO & ENSAYE \\
\hline APARTAR & ENSAYAR \\
\hline APURADOR & REPASADOR \\
\hline
\end{tabular}

La consecuencia última es que el corpus de Minería del $D R A E$ presenta palabras procedentes de textos literarios con más de trescientos años que ya no tienen un uso real, como azoguería, definida como «Oficina donde se hacen las operaciones de la amalgamación», magistral «Mezcla de óxido férrico y sulfato cúprico... que se emplea en el procedimiento americano de amalgamación», ahonde «Excavación de siete varas que, según las ordenanzas, debía hacerse a un plazo determinado en las minas de América, para conseguir la propiedad»; pero no recoge denominaciones actuales ${ }^{20}$ que cualquier persona curiosa puede encontrar en revistas, periódicos, páginas de Internet.

En cuanto a las definiciones lexicográficas, junto a las que responden con bastante rigor al paradigma científico, como pueden ser las ya vistas bismutita, andalucita o cementar «Meter barras de hierro en disolución de sales de cobre para precipitarlo», encontramos otras más propias de un diccionario general, como pega «Acción de pegar fuego a un barreno», pozo «Hoyo profundo para bajar a las minas». Además, en ocasiones, para definir una voz utiliza términos técnicos que en su respectiva entrada carecen de marca: como barrenero s.v. banderilla, cuña s.v. barretero, calcinación s.v. cochura, desmontes s.v. contramina, hormigo s.v. jabeca, copelación s.v. nata. En otras no recoge la acepción de la voz técnica que utiliza para definir; así s.v. amigo «Palo que se coloca atravesado en la punta del tiro o cintero para que, montándose los operarios bajen y suban por los pozos» utiliza cintero, voz que en su respectiva entrada no ofrece acepción alguna aplicable a la descripción de amigo.

20 Perforadoras, compósitos, encajante, remoción, buzamiento, tamiz, quilate métrico, etc. 
Quizá, como señalaba Paz Battaner en una reciente ponencia ${ }^{21}$, «el diccionario académico no le presta atención al tecnicismo popular» y el de la minería lo es, como otras actividades primarias. Quizá debiera desaparecer la marca actual de Minería, que en buena medida está siendo absorbida por ciencias y tecnologías nuevas, como la Protección del Medio Ambiente. Pero lo que no puede desaparecer son las voces que a lo largo del tiempo han servido para expresar todo lo relacionado con una de las ocupaciones más antiguas del hombre: quizá su sitio no esté en un diccionario general, pero han de tener un espacio en la lexicografía histórica especializada.

Los Prólogos de las distintas ediciones del DRAE nos transmiten la idea de que las voces científicas y técnicas son aceptadas, bien porque las sanciona el uso, bien por su presencia en textos literarios - autoridades-. Esos mismos Prólogos inciden en la voluntad de la institución de recoger vocablos «puestos en curso por los hallazgos de la ciencia y los progresos de la técnica» ${ }^{22}$, intención que en el caso de las palabras especializadas de minería no se ve reflejada en el Diccionario. Buena parte de los términos mineros allí incluidos han superado ya la fecha de caducidad y las propias definiciones dan cuenta de ello. Por el contrario, se evidencian algunas ausencias: no deja de sorprender el vacío en cuento la minería del carbón en la península.

\section{BIBLIOGRAFÍA ${ }^{23}$}

Acarete du Biscay, Relación de un viaje al Río de la Plata y de allí por tierra al perú con observaciones sobre los habitantes, sean indios o españoles, las ciudades, el comercio, la fertilidad y las riquezas de esta parte de América (traducción de Francisco Fernández Wallace) Buenos Aires, Alfer \& Vats.

Acosta, J. (1608), Historia natural y moral de las Indias : en que se tratan las cosas notables del cielo y elementos, metales, plantas y animales dellas y los ritos y ceremonias, leyes y gouierno y guerras de los Indios, Madrid, Alonso Martin.

Agrícola, J. (1556), De Re Metálica libri XII, Basilea.

Alonso BARBA, A. (1640), Arte de los metales en que se enseña el verdadero beneficio de los de oro y plata por açogue, el modo de fundirlos todos y cómo se han de refinar y apartar unos de otros, Madrid, Imprenta del Reyno.

21 En la Jornada Panlatina de Terminología, hablando de «Terminología y Diccionarios».

22 Prólogo al DRAE 1992.

23 Las obras citadas y de las que no ofrecemos referencia de página han sido consultadas a través de la versión digital que ofrece la Biblioteca Virtual Cervantes. 
Alonso GonZÁlez, A. (2002), «El Diccionario y maneras de hablar que se usan en las minas de García de Llanos: el comienzo de la terminología Minera en castellano», De historia de la lexicografía, La Coruña, Toxosoutos.

BARgallo, M. (1955), La minería y la metalurgia en la América española durante la época colonial, con un apéndice sobre la industria del hierro en México desde la iniciación de la Independencia hasta el presente, México

DCECH: Corominas, J; Pascual, J. A. (1980-1991). Diccionario crítico etimológico castellano e hispánico, Madrid, Gredos.

DíAz del CAstillo, B. (1632), Historia verdadera de la conquista de la Nueva España, Madrid, Imprenta del Reyno, [s.a.].

Diccionario de América (manuscrito del siglo XVIII que se conserva en la biblioteca de Palacio)

Diccionario de Autoridades, Real Academia Española (1739-1963), Madrid, Gredos (ed. facsímile, 1984).

GAMBOA, F. Javier de (1761), De la significación de algunas voces obscuras usadas en los minerales de Nueva España.

GUTIÉRREZ Rodilla, B. M. (1993), «Los términos relacionados con la medicina en el Diccionario de Autoridades», BRAE, 73, pp. 463-512.

GutiÉRrez Rodilla, B. M. (1994-1995). «Construcción y fuentes utilizadas para los términos médicos en el Diccionario de autoridades», Revista de Lexicografia, I, pp. 149-162.

GutiÉRrez Rodilla, B. M. (1998), La ciencia empieza en la palabra, Barcelona, Península.

GUTIÉRREZ RoDILLA, B. M. (1999), La constitución de la lexicografía médica moderna en España (1700-1910), La Coruña, Toxosouto.

Molina BARrios, R. (ed.) (1983), Diccionario y maneras de hablar que se usan en las minas, La Paz, MUSEF Editores

PÉRez de VArgas, B. (1562). De re metallica, Madrid, Pierres Cosin.

SÁnchez Gómez, J. (1989): De Minería, Metalurgia y Comercio de metales, Salamanca, Ediciones Universidad de Salamanca.

Stubbe: Stubbe, Carlos F. (1945), Vocabulario minero antiguo, Buenos Aires, Talleres Gráficos Miguel Violetto.

Terreros, E. (1786), Diccionario castellano con las voces de Ciencias y Artes, Madrid, Viuda de Ibarra (facsímile en Madrid, Arcos Libros, 1987)

Tesoro lexicográfico, edición digital (para la consulta de todas las ediciones del Diccionario de la Real Academia Española).

VAnoccio, B. (1540), De Pirotecnia libri X, Venecia. 